\title{
EFFECT OF A NEW COMPLEX MYCOTOXIN ADSORBENT ON GROWTH PERFORMANCE, AND SERUM LEVELS OF RETINOL, TOCOPHEROL AND 25-HYDROXYCHOLECALCIFEROL IN PIGS FED ON MYCOTOXIN- CONTAMINATED FEED
}

\author{
Rostyslav FAUSTOV1, Vadym LYKHACH ${ }^{2}$, Anna LYKHACH ${ }^{\star 凶}$, Mykola SHPETNY4, and Leonid LENKOV5 \\ 1.Department of Technology of Livestock Production, Faculty of Technology of Production and Processing of Livestock Products, Standardization and Biotechnology, \\ Mykolayiv National Agrarian University, Mykolayiv, Ukraine \\ 2Department of Technologies in Poultry, Pig and Sheep Breeding, Faculty of Livestock Raising and Water Bioresources, National University of Life and Environmental \\ Sciences of Ukraine, Kyiv, Ukraine \\ ${ }^{3}$ Department of Animal Biology, Faculty of Livestock Raising and Water Bioresources, National University of Life and Environmental Sciences of Ukraine, Kyiv, Ukraine \\ ${ }^{4}$ Department of Breeding and Selection of Animals and Aquatic Bio-resources, Faculty of Biology and Technology, Sumy National Agrarian University, Sumy, Ukraine \\ ${ }^{5}$ LLC "VetServiceProduct", Kyiv, Ukraine
}

Email: avlykhach@nubip.edu.ua; (D)ORCiD: 0000-0002-0472-6162

Supporting Information

ABSTRACT: The objective of the present study was to investigate the effects of commercial analogue mycotoxin adsorbent (CAMA) and Gepasorbex as a new complex mycotoxin-adsorbent additive on growth performance and serum retinol, tocopherol and 25-hydroxycholecalciferol concentrations of fattening young pigs $(n=90)$, which fed on the combined feed contaminated with mycotoxins. Animals were randomly allocated to 3 groups with 30 heads in each: the first group of pigs (control) fed the basic diet in grower and finisher periods; the second group fed the basic diet with the $0.15 \%$ by weight of feed of the mycotoxinsadsorbent as commercial analogue; the third group fed the basic diet with the addition of $0.15 \%$ by weight of feed of Gepasorbex, a new compound of mycotoxin-adsorbent additive. On the $48^{\text {th }}$ and $88^{\text {th }}$ days of fattening, blood samples were taken from the pigs for testing the vitamins $A, E$ and 25-hydroxycholecalciferol levels. Piglets from third experimental group followed by group 2 animals showed better growth rates and significantly $(P<0.001, P<0.01$, respectively) exceeded analogues from the control group in live weight and average daily gain in all age periods which showed a noticeable positive effect of diet's mycotoxin adsorbents, especially Gepasorbex, on animal growth rates. The results of the laboratory study showed that in the pigs from third experimental group, which fed on Gepasorbex with compound feed, the serum concentrations of retinol, tocopherol and 25-hydroxycholecalciferol were within the biological reference interval and significantly exceeded $(P<0.05)$ similar indicators from the control group in both periods. The results of the experiment showed that when animals are subjected to diets contaminated by mycotoxins, use of a new complex action preparation like Gepasorbex can mitigate the negative impacts of mycotoxins on animal performance, and is more capable to remove mycotoxins without binding to dietary vitamins.

Keywords: Gepasorbex, Mycotoxins, Retinol, Tocopherol, 25-hydroxycholecalciferol.

\section{INTRODUCTION}

It is known that the use of intensively innovative technologies and pigs of high genetic potential in order to ensure the productivity through efficient use of feed resources, maximum preservation of animals and prevention of various diseases is a feature of the modern pig industry (Caisin et al., 2011). This fact places significant demands on the provision of quality and environmentally friendly feed, which is associated with their contamination by various toxins, heavy metals, pesticides, nitrates, etc. (Bryden, 2012; Holanda et al., 2021). In commercial pig farms, the presence of mycotoxins in feed is, unfortunately, quite common. Therefore, various measures are used to prevent pigs' diseases caused by mycotoxins, as well as to reduce economic damage (Kanora and Maes, 2009). It should be noted that mycotoxins are toxic secondary metabolites formed by various fungi, such as Aspergillus, Penicillium and Fusarium, which can contaminate feeds and, consequently, food (Pierron et al., 2016; Conte et al., 2020; Hussain et al., 2020; Ulrikh and Smolovskaya, 2021).

Despite improvements in good agricultural and industrial practices, the mycotoxin contamination is unavoidable, and contaminants occur almost everywhere in varying concentrations and ratios in the diet of both animals and humans (Ramos and Hernandez, 1997; Bryden, 2012). Global climate change has resulted in unusual weather patterns, with increased frequency of drought, flooding and temperature extremes (Godde at al., 2021). These changes in weather all increase the chance of mycotoxin contamination of feed grains. Increased global trading of feed grains also increases the chance that blends of grains will result in combinations of different mycotoxins in a diet of animals (Mullan, 2017).

Currently, scientists from the world's best laboratories have isolated more than 300 to 400 mycotoxins with their laboratory identification of about 20 species (Pereira at al., 2019). Therefore, it was found that mycotoxins are a group of 
substances with different structure, which is a secondary metabolite of toxicogenic fungi. According to experts, $25 \%$ of world grain production shows contamination with mycotoxins (CAST, 2003; Eskola at al., 2019). In addition, these substances are involved in a number of toxic mechanisms, in particular: disruption of several metabolic functions in both humans and animals. Mycotoxicosis is common in pig breeding because pigs are quite sensitive to mycotoxins, where the latter affect the reduction of feed intake, the development of diseases of the reproductive organs, reproductive dysfunction, weakening the body's immune system, reducing resistance to diseases (coccidiosis, colibacillosis, etc.), the cost of preventive and veterinary measures, reducing the effectiveness of vaccines and drugs (D'Mello et al., 1999; Dersjant-Li et al., 2003). However, as noted the susceptibility of pigs to mycotoxicosis is influenced by a number of factors, such as: sex and age, and each mycotoxin has its own mechanism of action with specific clinical manifestations, according to the accepted amount (Cote et al., 1985; Roger and Coulombe, 1993; Hussein and Brasel, 2001). As a result, the losses from pig mycotoxicosis are considerable: a marked decrease in productivity, low reproductive capacity, high mortality, forced slaughter of pigs, which causes significant economic losses (Reddy et al., 2018). The parameters of the impact of mycotoxins on pigs are suppression of immune status, hepatotoxic and nephrotoxic effects, low consumption or complete refusal of feed, increased feed consumption, reduced live weight gain, gastrointestinal and cardiovascular disorders, high mortality, etc. (Holanda and Kim, 2020). It is unfortunate that the body does not produce antibodies to mycotoxins (Díaz-Llano and Smith, 2007).

In order to prevent mycotoxicosis in pigs, world scientists and practitioners have developed ways to minimize the action of mycotoxins aimed at removing mycotoxins with various mineral and organic adsorbents (Ramos and Hernandez, 1996; Huwig et al., 2001; Battacone et al., 2007; Holanda et al., 2021). Studies by a number of authors have shown that long-term use of sorbents revealed a decrease in the content of vitamins A, D and E in the blood of animals (Lawson et al., 1971; Harvey et al., 1994; Kihal et al., 2022).

Therefore, a number of studies are currently being conducted to find the most effective sorbents that will get rid of mycotoxins and preserve vitamins in animals. Due to the urgency of the problem, the study aimed to determine the effectiveness of use of a new complex mycotoxin-adsorbent additive Gepasorbex a product of VetServiceProduct in combined feeds contaminated with mycotoxins, to increase the productivity of pigs.

\section{MATERIALS AND METHODS}

\section{Ethical regulation}

The rules for the treatment of animals in the experiment were fully complied with European legislation on animal protection and comfort kept on farms (Directive № 95/58 EU "From the protection of farm animals" of the EU Council of 20.07.1998 as amended by EU Regulation № 806/203 of 14.04.2003, № 91/630 EU «Minimum standards for the protection of pigs" of 19.11.1991 as amended by EU Regulation). The protocol of experimental study on blood sampling in pigs, approved by the local Commission on Bioethics of the National University of Life and Environmental Sciences of Ukraine on Good Clinical Practice (GCP) for the protection and humane treatment of experimental animals.

\section{Experimental design}

A total of 90 heads fattening young pigs were used in the experiment, where the maternal form was a combination of the Large White $\times$ Landrace breeds, and the paternal form was boars of the Maxter terminal line. The animals were housed on the commercial farm of the Tavriya Pigs Limited Liability Company placed in Skadovsk district, Kherson region, Ukraine. Animals was divided into two grower and finisher periods: Grower period was included of animals (12-17 weeks old) with a live weight of 30-60 kg consumed 2.4-2.6 kg feed per head per day using the following grower feed type of nutritional value: crude protein $=166.7 \mathrm{~g} / \mathrm{kg}$ and exchange energy $=13.562 \mathrm{MJ} / \mathrm{kg}$. The pigs were placed on a concrete slotted floor with an area of $0.65 \mathrm{~m}^{2} /$ head. Finisher period of fattening was included of animals with a live weight of 61$100 \mathrm{~kg}$ (17-22 weeks old) consumed $2.8-3.0 \mathrm{~kg}$ feed per head per day using a combined feed type of nutritional value with $146.7 \mathrm{~g} / \mathrm{kg}$ crude protein and $13.411 \mathrm{MJ} / \mathrm{kg}$ exchange energy. The pigs were placed on a concrete slotted floor with an area of $0.85 \mathrm{~m}^{2} /$ head.

\section{Feeding}

As the basic diet (BD) it was used combined feed of own production for the use of premixes of production produced by Alternativa LLC. When transferring pigs from the rearing shop to the fattening shop of the first period, in order to equalize the animals and purity of research in the period from 11-12 weeks, the equalization period started. Then all experimental animals were divided into three groups (on the principle of analogues) of $\mathbf{3 0}$ heads: the control group of pigs fed the BD of both grower and finisher"; pigs of the second experimental group consumed the BD of both grower and finisher with the addition of $0.15 \%$ by weight of feed CAMA; and the third experimental group fed the BD of both grower and finisher with the addition of $0.15 \%$ by weight of feed complex preparation of Gepasorbex (Table 1 ).

The composition of $1 \mathrm{~kg}$ of Gepasorbex produced by VetServiceProduct LLC contains the following active ingredients (\%): silica dioxide (60.2-70.8); aluminum oxide (8.0-12.0); magnesium carbonate (1.0-2.5); titanium dioxide (0.8-0.15); selenium (0.32-0.35); clineopleolite (4.2-4.5); active fodder yeast (8.0-10.0); milk thistle Silybum marianum (18.0-20.0) (the registration certificate $=\mathrm{AB}-08268-04-19$ ). 
The main feed used for feeding pigs of the experimental groups according to laboratory studies was recognized as slightly toxic to aflatoxin B1 $(\leq 0,05 \mu \mathrm{g} / \mathrm{kg})$, ochratoxins $(\leq 0.1-0.4 \mu \mathrm{g} / \mathrm{kg})$ and zearalenone $(\leq 0.25 \mu \mathrm{g} / \mathrm{kg})$, contract №837 from 06.07.2021 (Expert Center of Diagnostics and Laboratory Support "Biolights" LLC, Kyiv region, Ukraine. In the experiment, fattening indexes were studied according to the methods (Ibatullin et al., 2017).

Table 1 - The scheme of the experiment

\begin{tabular}{lll}
\hline Age & Group & Feeding conditions \\
\hline Age 11-12 weeks - EW & & \\
\hline \multirow{3}{*}{ Age 12-17 weeks } & $1^{\text {st }}$, Control & BD for grower \\
& $2^{\text {nd }}$, Experimental & BD $+0.15 \%$ by weight of feed CAMA \\
& $3^{\text {rd }}$, Experimental & BD $+0.15 \%$ by weight of feed Gepasorbex \\
\hline \multirow{3}{*}{ Age 17-22 weeks } & $1^{\text {st }}$, Control & BD for finisher \\
& $2^{\text {nd }}$, Experimental & BD $+0.15 \%$ by weight of feed CAMA \\
& $3^{\text {rd }}$, Experimental & BD $+0.15 \%$ by weight of feed Gepasorbex \\
\hline
\end{tabular}

\section{Serum retinol, tocopherol and 25-hydroxycholecalciferol measurement}

At 12, 14, 17 and 22 weeks, live weight (in $\mathrm{kg}$ ) and average daily gain (in g) were measured. On the 48 $\frac{\text { th }}{}$ and $88^{\text {th }}$ days, 30 blood samples were taken from pigs of the experimental groups, on an empty stomach in the morning by puncture of the jugular vein to determine the contents of retinol, tocopherol and 25-hydroxycholecalciferol. Serum samples for the content of these vitamins were conducted in the independent laboratory of Expert Center of Diagnostics and Laboratory Support "Biolights" LLC, Kyiv. Vitamins A and E were examined by high performance liquid chromatography, analyzer and Agilent 1200 HPLC System with UV-detector; Recipe complete Kit (Germany), the detection wavelength for the determination of vitamin A was $328 \mathrm{~nm}$ and for vitamin $\mathrm{E}$ it was $286 \mathrm{~nm}$. The flow rate was 0.750 $\mathrm{ml} / \mathrm{min}$., the temperature of the column thermostat $+30.0^{\circ} \mathrm{C}$, and 25-hydroxycholecalciferol measured by electrochemiluminescence immunoassay (ECLIA) method, Cobes e 601 analyzer, Roche Diagnostics system (Germany).

\section{Statistical analysis}

Data were analyzed using Statistica 12.0 (StatSoft Inc., 2014, www.statsoft.com). Results are presented as mean \pm standard deviation $(X \pm S D)$. The following significance levels were used for the study: $P<0.05 ; 0.01$ and 0.001 .

\section{RESULTS AND DISCUSSION}

A significant difference in productive traits (live weight and average daily gain) of pigs of the control and experimental groups was observed at the age of 56 days, or at 14 weeks (Table 2). It should be noted that all piglets had a live weight of 33-34 kg when put to fattening. During 14-weeks piglets from third experimental group fed on Gepasorbex significantly $(P<0.05)$ by $1.93 \mathrm{~kg}$ in live weight exceeded from the control group; for average daily gain significantly $(P<0.001)$ exceeded by $114.3 \mathrm{~g}$ from the control group and by $50 \mathrm{~g}(\mathrm{P}<0.05)$ over the second group fed CAMA. Regarding the $17^{\text {th }}$ weeks: the animals of the third experimental group significantly $(P<0.05)$ exceeded the live weight by $2.3 \mathrm{~kg}$ over the piglets of the second experimental group and by $3.63 \mathrm{~kg}(\mathrm{P}<0.001)$ over to the analogues of the control group. In the piglets of the control and second experimental groups, the average daily weight gain was significantly lower by $81.0 \mathrm{~g}$ $(P<0.001)$ and $38.1 \mathrm{~g}(\mathrm{P}<0.05)$, respectively, than in pigs of the third experimental group. At the age of 22 weeks of fattening, young pigs of the second and third experimental groups had a significantly advantage in live weight by $2.47 \mathrm{~kg}$ $(P<0.01), 5.10 \mathrm{~kg}(P<0.001)$ and average daily gain by $32.36 \mathrm{~g}(\mathrm{P}<0.05), 41.90 \mathrm{~g}(\mathrm{P}<0.01)$ over control group.

\section{Table 2 - Productive traits of experimental groups of pigs}

\begin{tabular}{|c|c|c|c|c|}
\hline \multicolumn{2}{|r|}{ Group / Age, $(n=30)$} & $1^{\text {st }}$, control & $2^{\text {nd }}$, experimental & $3^{\text {rd }}$, experimental \\
\hline 12 weeks & Live weight, $\mathrm{kg}$ & $35.50 \pm 0.717$ & $35.03 \pm 0.812$ & $35.83 \pm 0.649$ \\
\hline \multirow{2}{*}{14 weeks } & Live weight, $\mathrm{kg}$ & $45.80 \pm 0.637$ & $46.23 \pm 0.768$ & $47.73 \pm 0.629^{*}$ \\
\hline & Average daily gain, $\mathrm{g}$ & $735.7 \pm 15.75$ & $800.0 \pm 19.19^{* *}$ & $850.0 \pm 12.04^{* * * a}$ \\
\hline \multirow{2}{*}{17 weeks } & Live weight, kg & $62.87 \pm 0.610$ & $64.20 \pm 0.791$ & $66.50 \pm 0.645^{\star * \star a}$ \\
\hline & Average daily gain, $g$ & $812.7 \pm 15.64$ & $855.6 \pm 10.33^{*}$ & $893.7 \pm 8.45^{\star * \star b}$ \\
\hline \multirow{2}{*}{22 weeks } & Live weight, kg & $93.33 \pm 0.471$ & $95.80 \pm 0.720^{* *}$ & $98.43 \pm 0.544^{* * * b}$ \\
\hline & Average daily gain, g & $870.5 \pm 11.92$ & $902.86 \pm 9.55^{*}$ & $912.40 \pm 8.55^{\star *}$ \\
\hline
\end{tabular}


Table 3 - Dynamics of the content of vitamins in the blood serum of pigs

\begin{tabular}{|c|c|c|c|c|}
\hline \multirow[b]{2}{*}{ The name of vitamins, unit } & \multicolumn{3}{|c|}{ Group, $(n=10) /$ vitamin content } & \multirow{2}{*}{$\begin{array}{l}\text { Biological } \\
\text { reference interval }\end{array}$} \\
\hline & $\begin{array}{c}1^{\text {st }} \\
\text { control }\end{array}$ & $\begin{array}{c}2^{\text {nd }}, \\
\text { experimental }\end{array}$ & $\begin{array}{c}3^{\text {rd }}, \\
\text { experimental }\end{array}$ & \\
\hline \multicolumn{5}{|l|}{ Age of pigs - 12 weeks (48 days) } \\
\hline Retinol (vitamin A), $\mu \mathrm{g} / \mathrm{mL}$ & $25.16 \pm 1.28$ & $25.84 \pm 1.39$ & $27.12 \pm 1.65$ & 27.0-30.0 \\
\hline Tocopherol (vitamin E), $\mu \mathrm{g} / \mathrm{mL}$ & $3.76 \pm 0.52$ & $4.28 \pm 0.39$ & $5.71 \pm 0.96^{*}$ & $5.7-6.4$ \\
\hline 25-hydroxycholecalciferol (vitamin D), ng/mL & $25.42 \pm 1.54$ & $25.75 \pm 1.38$ & $31.05 \pm 2.12^{*}$ & $30.0-32.0$ \\
\hline \multicolumn{5}{|l|}{ Age of pigs - 22 weeks (88 days) } \\
\hline Retinol (vitamin A), $\mu \mathrm{g} / \mathrm{mL}$ & $36.13 \pm 1.82$ & $42.29 \pm 1.67^{*}$ & $52.88 \pm 1.95^{\star * *}$ & $50.0-60.0$ \\
\hline Tocopherol (vitamin E), $\mu \mathrm{g} / \mathrm{mL}$ & $5.02 \pm 0.37$ & $5.64 \pm 0.29$ & $6.62 \pm 0.54^{*}$ & $6.5-6.8$ \\
\hline 25-hydroxycholecalciferol (vitamin D), ng/mL & $27.24 \pm 0.87$ & $28.15 \pm 0.92$ & $30.89 \pm 1.14^{*}$ & $30.0-32.0$ \\
\hline
\end{tabular}

Of the several authors that the use of feeds with the addition of mycotoxin adsorbents in groups of animals improved their growth characteristics (Huwig et al., 2001; Duan et al., 2014; Patience et al., 2014; Weaver et al., 2014; Frobose et al., 2017). Noted that the use of phytobiotics with adsorbent of mycotoxin to mitigate the negative effects of multiple mycotoxins in pig diets increased their productivity, improved the absorption of feed elements and had better biochemical parameters of hepatic metabolism and immune status of pigs (Holanda et al., 2021)

It should be noted that adsorbents of mycotoxins differ from each other and from generation to generation due to technological developments are becoming more sophisticated and diverse in adsorption properties, as well as show an indirect therapeutic effect. Feed sorbents have the ability to quickly bind a wide range of toxicants. Sorbents are stable at different $\mathrm{pH}$ values, thermostable during feed granulation. The use of mycotoxin adsorbents as feed additives is beneficial for reducing the toxic effects of mycotoxins in pigs, which provides a more sustainable use of feed. There are many mechanisms by which adsorbents mitigate the toxic effects of mycotoxins in feed, one of which is adsorption when the mycotoxin interacts with another molecule (adsorbent) and is not absorbed by animals (Boudergue et al., 2009).

In the adsorbed form, the mycotoxin will be excreted in the feces, and its toxic effects will be minimized in animals. The next mechanism is the use of these agents to strengthen the immune function and intestinal health of the animal, such agents often include the use of prebiotics, probiotics, postbiotics, phytobiotics and synbiotics (Holanda and Kim, 2020).

However, many feed additives with sorption properties bind vitamins, macro- and micronutrients (Papaioannou et al., 2002; Kihal et al., 2021). According to the results of studies by other authors, it has been proven that long-term use of sorbents revealed a decrease in the content of vitamins A, D and E in blood of animals and poultry. Aflatoxin-B1 caused detrimental effects on liver health and electrolyte balance in pigs, leading to impaired liver function and structure of the liver and kidneys (Schell et al., 1993). The productivity and resistance of piglets depends on providing them with sufficient nutrients and biologically active substances. The latter include vitamins A, D and E, which ensure the normal course of biochemical and physiological processes in the body, have an impact on the growth and development of animals (Kihal et al., 2022).

As a result of experimental studies, it was found out a decrease in the content of some vitamins in the pigs of control and second experimental groups over animals of third experimental group (Table 3). On 48 ${ }^{\text {th }}$ and $88^{\text {th }}$ days, in the pigs of the third experimental group, serum concentrations of retinol $(27.12 \mu \mathrm{g} / \mathrm{mL}$ and $52.88 \mu \mathrm{g} / \mathrm{mL})$, tocopherol $(5.71 \mu \mathrm{g} / \mathrm{mL}$ and $6.62 \mu \mathrm{g} / \mathrm{mL}), 25$-hydroxycholecalciferol $(31.05 \mathrm{ng} / \mathrm{mL}$ and $30.89 \mathrm{ng} / \mathrm{mL}$ ) respectively, detected within the biological reference interval. This indicates the effect of Gepasorbex on the relative bioavailability of these vitamins in the body of pigs third experimental group.

On the $48^{\text {th }}$ and $88^{\text {th }}$ days, the piglets of the second experimental group fed CAMA relative to the minimum value of the biological reference interval reduced serum concentrations, \%: retinol ( $\downarrow 4.3$ and $\downarrow 15.4)$, tocopherol ( $\downarrow 24.9$ and $\downarrow 13.2$ ), 25-hydroxycholecalciferol ( $\downarrow 14.2$ and $\downarrow 6.2$ ). A similar trend was noted in the animals of the control group on the 48 $\frac{\text { th }}{}$ and 88 th days - a decreased of serum retinol ( $\downarrow 6.8 \%$ and $\downarrow 27.7 \%$ ), tocopherol ( $\downarrow 34.0 \%$ and $\downarrow 22.8 \%)$, 25-hydroxycholecalciferol ( $\downarrow 15.3 \%$ and $\downarrow$ 9.2\%) relative to the minimum value of the biological interval.

Given that retinol, in addition to its antioxidant function, stimulates the growth of connective tissue ("growth vitamin"), its deficiency often reduces weight gain (see Table 2). It is postulated that the decrease in vitamin A levels in the liver is the result of the consumption of T-2 toxin (Dvorska and Surai, 2001) and, as a consequence, a decrease in intestinal absorption of fat-soluble nutrients. Hoehler et al. (1996) suggested that mycotoxins, by stimulating lipid peroxidation of intestinal enterocytes, lead to the damage that significantly contributes to the disruption of retinol absorption. In our studies, this clearly observed in the pigs of control group.

In turn, the researchers noted that the presence of ochratoxin A in the diet significantly reduced the concentration of 
$\alpha$-tocopherol in the liver. In addition, aflatoxin in pig diets reduced serum tocopherol and retinol concentration compared to control and pre-test values and decreased tocopherol concentration in cardiac tissue, which was recorded with animals of control group in the experiment (Harvey et al., 1994). Similar results were obtained by Ponchon et al. (1969), Lawson et al. (1971) on the negative effect of feed mycotoxins in animal diets on the inhibition of cholesterol synthesis, and subsequently on the activation of vitamin $\mathrm{D}$, calcium and phosphorus balance in pigs.

\section{CONCLUSION}

The results of the experiment show that a new complexes mycotoxin adsorbent a positive influence on the growth performance of piglets, increasing the bioavailability of retinol, tocopherol and 25-hydroxycholecalciferol in the body of pigs. The recommended rate a new complexes mycotoxin adsorbent for young fattening pigs is $0.15 \%$ by weight of feed. This result can be used in pig farming and also there is a need to study a feed costs and economic efficiency of using a new complexes mycotoxin adsorbent.

\section{DECLARATIONS}

\section{Corresponding author}

E-mail: avlykhach@nubip.edu.ua

\section{Authors' contribution}

F.Rostyslav and L.Vadym participated in the design of study, performed the experiments and writing original manuscript. L.Anna, Sh.Mykola and L.Leonid assisted in performing the study, data arranging, and calculation. L.Vadym and L.Anna critically revised the manuscript. All authors have read and agreed to the published version of the manuscript.

\section{Acknowledgements}

The experimental studies performed within the state budget of the Ministry of Education and Science of Ukraine (state registration number 0119U001042, 2019-2021). The authors would like to thank the owner, employees of the commercial farm where the experimental study was conducted and VetServiceProduct LLC.

\section{Conflict of interests}

The authors have not declared any conflict of interests.

\section{REFERENCES}

Battacone G, Carboni GA, Nicolussi P, Ligios C, Pulina G (2007). Use of a glucomannan polymer to reduce the effects of mycotoxin-contaminated diets in finishing pigs. Italian Journal of Animal Science, 6(1): 673-675. Article Link I DOI: https://doi.org/10.4081/ijas.2007.1s.673

Boudergue C, Dragacci S, Favrot M-Ch, Fremy J-M, Massimi C, Prigent P, Debongnie, Pussemier L, Boudra H, Morgavi D, Oswald I, Perez A, Avantaggiato G (2009). Review of mycotoxin-detoxifying agents used as feed additives: mode of action, efficacy and feed/food safety. In: Scientific report submitted to EFSA. 6(9): 22E. Article Link

Bryden WL (2012). Mycotoxin contamination of the feed supply chain: Implication of animal productivity and feed security. Animal Feed Science and Technology, 173(1-2): 134-158. DOI: https://doi.org/10.1016/j.anifeedsci.2011.12.014 I Article Link

Caisin L, Harea V, Bivol L (2011). Using enterosorbent Praimix Alfasob in feeding growing piglets. In: Scientific Papers, UASVM of Bucharest. Series D: Animal science, LIV: 25-30. Article Link

Conte G, Fontanelli M, Galli F, Cotrozzi L, Pagni L, and Pellegrini E (2020). Mycotoxins in feed and food and the role of ozone in their detoxification and degradation: an update. Toxins, 12(8): 486. Article Link I DOI: https://doi.org/10.3390/toxins12080486.

Cote LM, Beasley VR, Bratich PM, Swanson SP, Shivaprasad HL, Buck WB (1985). Sex-related reduced weight gains in growing swine fed diets containing deoxynivalenol. Journal of Animal Science, 61: 942-950. Article Link I DOI: https://doi.org/10.2527/jas1985.614942x

Council for Agricultural Science and Technology (CAST) (2003). Mycotoxins: risks in plant, animal, and human systems. Task Force Report № 139. Ames, IA, USA. Link: https://tinyurl.com/yyonen6I.

D'Mello JPF, Placinta CM, Macdonald AMC (1999). Fusarium mycotoxins: a review of global implications for animal health, welfare and productivity. Animal Feed Science and Technology, 80: 183-205. Article Link

Dersjant-Li Y, Verstegen MWA, Gerrits WJJ (2003). The impact of low concentrations of aflatoxin, deoxynivalenol or fumonisin in diets on growing pigs and poultry. Nutrition Research Reviews, 16: 223-239. Article Link I DOI: https://doi.org/10.1079/NRR200368

Díaz-Llano G, Smith TK (2007). The effects of feeding grains naturally contaminated with Fusarium mycotoxins with and without a polymeric glucomannan adsorbent on lactation, serum chemistry, and reproductive performance after 
weaning of first-parity lactating sows. Journal of Animal Science, 85(6): 1412-1423. Article Link I DOI: https://doi.org/10.2527/jas.2006-213

Duan J, Yin J, Wu M, Liao P, Deng D, Liu G, et al. (2014). Dietary glutamate supplementation ameliorates mycotoxin-induced abnormalities in the intestinal structure and expression of amino acid transporters in young pigs. PLoS ONE, 9(11): e112357. Article Link I DOI: https://doi.org/10.1371/journal.pone.0112357

Dvorska JE, Surai PF (2001). Effects of T-2 toxin, zeolite and Mycosorb on antioxidant systems of growing quail. AsianAustralasian Journal of Animal Sciences, 14(12): 1752-1757. $\underline{\text { Article Link I }}$ DOI:https://doi.org/10.5713/ajas.2001.1752

Eskola M, Kos G, Elliott ChT, Hajslova J, Mayar S and Krska R (2020). Worldwide contamination of food-crops with mycotoxins: Validity of the widely cited 'FAO estimate' of 25\%. Critical Reviews in Food Science and Nutrition, 60(16): 2773-2789. Article Link I DOI: https://doi.org/10.1080/10408398.2019.1658570

Frobose HL, Stephenson EW, Tokach MD, DeRouchey JM, Woodworth JC, Dritz SS, Goodband RD (2017). Effects of potential detoxifying agents on growth performance and deoxynivalenol (DON) urinary balance characteristics of nursery pigs fed DON-contaminated wheat. Journal of Animal Science, 95(1): 327-337. Article Link I DOI: https://doi.org/10.2527/jas.2016.0664

Godde CM, Mason-D'Croz D, Mayberry DE, Thornton PK, Herrero M (2021). Impacts of climate change on the livestock food supply chain; a review of the evidence. Global Food Security, 28: 100488. Article Link I DOI: https://doi.org/10.1016/j.gfs.2020.100488

Harvey RB, Kubena LF, Elissalde MH (1994). Influence of vitamin E on aflatoxicosis in growing swine. American Journal of Veterinary Research, 55(4): 572-577. Article Link I DOI: https://pubmed.ncbi.nlm.nih.gov/8017706/

Hoehler D, Marquardt RR, McIntosh AR, Xiao H (1996). Free radical generation as induced by ochratoxin A and its analogs in bacteria (Bacillus brevis). Journal of Biological Chemistry, 271(44): 27388-27394. Article Link: https://www.jbc.org/article/S0021-9258(18)35245-1/pdf

Holanda DM and Kim SW (2020). Efficacy of mycotoxin detoxifiers on health and growth of newly-weaned pigs under chronic dietary challenge of deoxynivalenol. Toxins, 12(5): 311. Article Link I DOI: https://doi.org/10.3390/toxins12050311

Holanda DM, Kim SW (2021). Mycotoxin occurrence, toxicity, and detoxifying agents in pig production with an emphasis on deoxynivalenol. Toxins, 13: 171. Article Link I DOI: https://doi.org/10.3390/toxins13020171

Holanda DM, Kim Y I, Parnsen W, Kim SW (2021). Phytobiotics with adsorbent to mitigate toxicity of multiple mycotoxins on health and growth of pigs. Toxins, 13(7): 442. Article Link I DOI: https://doi.org/10.3390/toxins13070442

Hussain T, Saleemi MK, Khan MZ, Khan A, Abbas RZ, Bilal MQ, Deeba F, Irshad H, Fatima Z, Afzal F, Farooq U (2020). Toxicopathological effects of endosulfan in female Japanese Quails (Coturnix japonica). Advancements in Life Sciences, 7(2): 72-78. Article Link: http://www.als-journal.com/articles/vol7issue2/721.20/866.pdf

Hussein HS, Brasel JM (2001). Toxicity, metabolism, and impact of mycotoxins on humans and animals. Toxicology, 167(2), 101-134. Article Link I DOI: https://doi.org/10.1016/s0300-483x(01)00471-1

Huwig A, Freimund S, Kaäppeli O, Dutler H (2001). Mycotoxin detoxication of animal feed by different adsorbents. Toxicology Letters, 122(2): 179-188. Article Link I DOI: https://doi.org/10.1016/s0378-4274(01)00360-5

Ibatullin II, Zhukorsky OM, Bashchenko MI (2017). Methodology and organization of scientific achievements on animal husbandry. Kyiv. pp. 328. Article Link

Kanora A, Maes D (2009). The role of mycotoxins in pig reproduction: a review. Veterinarni Medicina, 54(12): 565-576. Article Link I DOI:https://doi.org/10.17221/156/2009-VETMED

Kihal A, Margues C, Rodrigues-Prado M, Jose-Cunileras E and Calsamiglia S (2022). Effect of diet supplementation with the mycotoxin binder montmorillonite on the bioavailability of vitamins in dairy cows. Toxins, 14(1): 26. Article Link I DOI: https://doi.org/10.3390/toxins14010026

Kihal A, Rodríguez-Prado ME, Cristofol C, Calsamiglia S (2021) Short communication: quantification of the effect of mycotoxin binders on the bioavailability of fat-soluble vitamins in vitro. Animals, 11(8): 2251. Article Link I DOI: https://doi.org/10.3390/ani11082251

Lawson DEM, Fraser DR, Kodicek E, Morris HR and Williams DH (1971). Identification of 1,25-dihydroxycholecalciferol, a new kidney hormone controlling calcium metabolism. Nature Cell Biology, 230: 228-230. Article Link: https://www.nature.com/articles/230228a0

Mullan B (2017). Mycotoxins in pig production. Agriculture and Food. Article Link: https://www.agric.wa.gov.au/feedingnutrition/mycotoxins-pig-production

Papaioannou DS, Kyriakis SC, Papasteriadis A, Roumbies N, Yannakopoulos A. Alexopoulos C (2002). Effect of in-feed inclusion of a natural zeolite (clinoptilolite) on certain vitamin, macro and trace element concentrations in the blood, liver and kidney tissues of sows. Research in Veterinary Science, 72(1): 61-68. Article Link I DOI: https://doi.org/10.1053/rvsc.2001.0524

Patience JF, Myers AJ, Ensley S, Jacobs BM, Madson D (2014). Evaluation of two mycotoxin mitigation strategies in growfinish swine diets containing corn dried distillers' grains with solubles naturally contaminated with deoxynivalenol. Journal of Animal Science, 92(2): 620-626. Article Link I DOI: https://doi.org/10.2527/jas.2013-6238

Pereira KS, Chunha SC and Fernandes JO (2019). Prevalent mycotoxins in animal feed: Occurrence and analytical methods. Toxins, 11(5): 290. Article Link I DOI: https://doi.org/10.3390/toxins11050290

Pierron A, Alassane-Kpembi I, Oswald IP (2016). Impact of mycotoxin on immune response and consequences for pig health. Animal Nutrition, 2(2): 63-68. Article Link I DOI: https://doi.org/10.1016/j.aninu.2016.03.001

Ponchon G, Kennan AL, DeLuca HF (1969). Activation of vitamin D by the liver. Journal of Clinical Investigation, 48: 20322037. Article Link I DOI: https://doi.org/10.1172/JCl106168 
Ramos AJ, Hernandez E (1996). In vitro aflatoxin adsorption by means of a montmorillonite silicate. A study of adsorption isotherms. Animal Feed Science Technology, 62: 263-269. Article Link I DOI: http://dx.doi.org/10.1016/S03778401(96)00968-6

Ramos AJ, Hernandez E (1997). Prevention of aflatoxicosis in farm animals by means of hydrated sodium calcium aluminosilicate addition to feedstuffs. A review. Animal Feed Science Technology, 65(1-4): 197-206. Article Link I DOI: https://doi.org/10.1016/S0377-8401(96)01084-X

Reddy KE, Song J, Lee HJ, Kim M, Kim DW, Jung HJ, Kim B, Lee Y, Yu D, Oh YK, Lee SD (2018). Effects of high levels of deoxynivalenol and zearalenone on growth performance, and hematological and immunological parameters in pigs. Toxins, 10(3): 114. Article Link I DOI: https://doi.org/10.3390/toxins10030114

Roger A, Coulombe JR (1993). Biological action of mycotoxins. Journal of Dairy Science, 76(3): 880-891. Article Link I DOI: https://doi.org/10.3168/ids.S0022-0302(93)77414-7

Schell TC, Lindemann MD, Kornegay ET, Blodgett DJ (1993). Effects of feeding aflatoxin-contaminated diets with and without clay to weanling and growing pigs on performance, liver function, and mineral metabolism. Journal of Animal Science, 71(5): 1209-1218. Article Link I DOI: https://doi.org/10.2527/1993.7151209x

Ulrikh EV and Smolovskaya OV (2021). Mycotoxins in fodder and its importance on safety of feed and the health of farm animals: a review. Online Journal of Animal and Feed Research, 11(6): 219-223. Article Link I DOI: https://dx.doi.org/10.51227/ojafr.2021.32

Weaver AC, See MT, Kim SW (2014). Protective Effect of two yeast based feed additives on pigs chronically exposed to Deoxynivalenol and Zearalenone. Toxins, 6(12): 3336-3353. DOI: https://dx.doi.org/10.3390/toxins6123336 I Article Link 